\title{
Poly(lactic acid-co-glycolic acid) Nanospheres Improved the Oral Delivery of Candesartan Cilexetil
}

\author{
Anroop B Nair1, Bandar E Al-Dhubiab1, Jigar Shah², Mahesh Attimarad', Sree Harsha1 \\ ${ }^{1}$ Department of Pharmaceutical Sciences, College of Clinical Pharmacy, King Faisal University, Al-Ahsa, KINGDOM OF SAUDI ARABIA. \\ ${ }^{2}$ Institute of Pharmacy, Nirma University, Ahmedabad - 382481, Gujarat, INDIA.
}

\begin{abstract}
Purpose: Certain physicochemical characteristics of Candesartan Cilexetil (CC) lead to incomplete oral absorption and poor clinical efficacy. This study assessed the prospect of the use of drug-embedded nanospheres to augment the oral bioavailability of CC. Methods: Baseline studies were conducted to measure the solubility of CC in the polymer. Drug encapsulated poly(lactic acid-co-glycolic acid) nanospheres were prepared by emulsion solvent evaporation method. Five different formulations (C1-C5) were prepared for the varying amount of CC (30-50 mg). Evaluation was carried out for nanospheres characters, drug dissolution and release kinetics. Pharmacokinetics parameters were evaluated in rat model. Results: Solubility of drug in polymer was $\sim 20$ $\mathrm{mg} / 100 \mathrm{mg}$ of poly(lactic acid-co-glycolic acid). Values of particle size (200-400 nm), zeta potential ( $\sim 25$ to $-27 \mathrm{mV}$ ) and polydispersity index $(0.17$ to 0.21$)$ were optimal for oral absorption. Morphological studies suggest that the prepared nanospheres were spherical in shape with no aggregation. The nanospheres exhibited biphasic release of CC with an initial burst effect $(\sim 50 \%$ in $4 \mathrm{~h})$, while it was low and incomplete $(\sim 54 \%$ in $14 \mathrm{~h}$ ) with pure drug. Furthermore, drug release from nanospheres appeared to indicate a Korsmeyer-Peppas model $(r 2=0.981)$, and diffusion of the drug molecules was by anomalous transport $(n=0.74)$. Greater and rapid absorption of CC was observed from the nanospheres with significantly higher $C_{\max }(599.92 \pm 139.36 \mathrm{ng} / \mathrm{ml} ; \mathrm{P}<0.0005)$ and $\mathrm{AUCO}_{-\infty}(\sim 3$ folds; $\mathrm{P}<0.0001)$ relative to the pure drug (control). Conclusion: These results suggested that $\mathrm{CC}$ loaded nanospheres seems to be a suitable alternative to improve the oral bioavailability and could be further assessed for clinical use.

Key words: Nanospheres, Release, Polymer, Evaluation, in vivo, Bioavailability.
\end{abstract}

\section{INTRODUCTION}

Hypertension is a global epidemic and is one of the major health challenges in the $21^{\text {st }}$ century. More than one billion individuals are currently estimated to be living with abnormally raised blood pressure worldwide, and $\sim 8$ million deaths occurs every year due to uncontrolled hypertension. ${ }^{1}$ The overall prevalence of hypertension is projected to rapidly increase to $\sim 2$ billion people by $2025 .^{1}$ Prospective observational studies show that the risk of cardiovascular increases in a linear fashion in hypertensive patients and is the most significant risk factor for cardiovascular morbidity and mortality. ${ }^{2}$ In addition, chronic complications of hypertension is a leading risk factor for retinal hemorrhage, ischemic and hemorrhagic stroke, myocardial infarction, heart failure, cerebrovascular diseases and chronic kidney diseases. ${ }^{3}$ The prevalence of hypertension increases with age and is strongly associated with economic growth, lifestyle changes, urbanization, among all the key risk factors. It is well documented that hypertension is also associated with substantial economic burden at the individual, family and societal levels. ${ }^{4}$ Five major categories of antihypertensive agents are used alone or in combination for the initiation and maintenance of antihypertensive treatment. Angiotensin receptor antagonists are widely indicated for the management of essential hypertension
Submission Date: 19-07-2017; Revision Date: 29-04-2017; Accepted Date: 07-06-2017

DOI: 10.5530/ijper.51.4.86 Correspondence: Anroop B Nair

Assistant Professor, Department of Pharmaceutical

Sciences, College of Clinical Pharmacy, King Faisal University, P.O. 400 AlAhsa-31982, KINGDOM OF SAUDI ARABIA.

Tel: 966-536-219-868 E-mail: anair@kfu.edu.sa

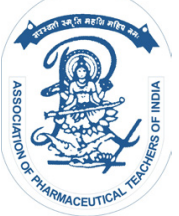

www.ijper.org 
and heart failure and is a major therapeutic option in the first line treatment of hypertension. ${ }^{5}$ Typically they are selective blockers of angiotensin II type 1 receptor and are well tolerated in humans. ${ }^{6}$ Among various angiotensin II receptor antagonists, a candesartan, non-peptide tetrazole derivative, is most widely preferred owing to its selective and competitive binding to angiotensin-II type 1 receptor, higher tolerance, long duration of action, greater efficacy and fewer side effects. In addition, this drug is the primary alternative choice in patients not responding to or intolerant of other antihypertensive drug classes. ${ }^{8}$ However, the clinical efficacy of candesartan cilexetil (CC) following oral therapy is limited by low and variable systemic delivery due to its physicochemical properties as well as physiological factors. ${ }^{9} \mathrm{CC}$ is categorized by biopharmaceutics classification system as a class II due to its low solubility across the physiological $\mathrm{pH}$ range, and this is associated with incomplete absorption from the gastrointestinal tract. ${ }^{10}$ Several formulation approaches have been assessed to improve the oral bioavailability of CC. In one approach, various prodrugs of candesartan were synthesized and CC was identified as most effective. ${ }^{11}$ However, the oral bioavailability of CC was found to be low $(\sim 15 \%-40 \%)$. Alternatively, solid lipid nanoparticles, self-micro emulsifying drug delivery system, nanoemulsion, solid dispersion and complexation were attempted to enhance solubility and bioavailability of this drug, but seems to be moderately effective. ${ }^{12,13}$

The oral therapy is the most desired and patient convenient route of drug administration as it offers significant advantages over any other existing route. ${ }^{14}$ Approximately $50 \%$ of dosage forms in market are oral based delivery systems. However, the conventional oral therapy of certain pharmaceutical actives is limited by poor solubility and stability in gastrointestinal tract, presystemic metabolism, low intestinal permeability, and inadequate drug release which leads to low oral bioavailability. ${ }^{15}$ Several novel approaches have been investigated to enhance intestinal absorption and higher systemic availability of some poorly bioavailable drugs. ${ }^{16,17}$ The oral controlled-release dosage forms have received much attention in the recent past due to their clinical advantages in comparison to the immediate release dosage forms. The potential of nanoparticulate drug delivery systems to enhance efficiency of pharmaceutical actives with substantially low oral bioavailability has captivated the interest of many researchers over the last decade. Typically, polymeric nanoparticles are drug carriers which are prepared with established polymers which encapsulate drug molecules in nano size range. ${ }^{18}$ Indeed, these nano-sized carriers overcome intrinsic challenges encountered by drug molecules in gastrointestinal tract, and can also be modified to maintain the required drug release for therapeutic response. ${ }^{19}$ Wide range of biocompatible polymers from synthetic and natural sources with specific properties have been explored for the formulation of nanoparticles intended for oral delivery. Among these, synthetic polymers are widely preferred as they possess good mechanical strength and can be modified to obtain well-defined release characteristics. ${ }^{20}$ In addition they also exhibit good biocompatibility, biodegradability, low toxicity and reduced susceptibility to enzymatic degradation. Hence, it is hypothesized that polymeric nanoparticles could be a potentially effective system for delivering CC by oral route. The objective of this study was to design and develop an effective nanosized polymeric carrier system, and assess its effectiveness in improving the oral bioavailability of $\mathrm{CC}$. The characteristics of the prepared polymeric nanoparticles were assessed and evaluated its effectiveness by measuring the pharmacokinetic parameters in vivo in rats.

\section{MATERIALS AND METHODS}

\section{Materials}

CC, poly(lactic acid-co-glycolic acid) (PLGA, 50:50), potassium dihydrogen phosphate, polyvinyl alcohol (PVA), methanol, triethanolamine, tween 20 , acetonitrile, methylene chloride were purchased commercially from Sigma Aldrich St. Louis, MO, USA.

\section{Analytical method}

Chromatographic separation and quantification of CC was carried out using a high performance liquid chromatography (HPLC) system (Shimadzu, Tokyo, Japan) comprising of a 20 AT pump, along with UV detector and column oven. Samples were measured using a system consisting of a Symmetry C18 analytical column $(4.6 \times 150 \mathrm{~mm}, 5.0 \mu \mathrm{m})$. Mobile phase was methanol and $20 \mathrm{mM}$ potassium dihydrogen phosphate (70:30) adjusted with triethanolamine to a $\mathrm{pH}$ of 6 . The flow of mobile phase was adjusted to $1.0 \mathrm{ml} / \mathrm{min}$ at room temperature and measured at $255 \mathrm{~nm}$ wavelength. ${ }^{21}$ Specific volume of samples $(25 \mu \mathrm{l})$ were injected $\left(20-2000 \mathrm{ng} / \mathrm{ml}, \mathrm{r}^{2}=0.986\right)$ and the retention time was $5.1 \mathrm{~min}$. Method was validated for linearity, accuracy, specificity, limit of quantification and limit of detection.

\section{Drug solubility}

Solubility of CC in PLGA polymer matrix was determined by weighing polymer $(100 \mathrm{mg})$, drug $(1-40 \mathrm{mg})$ and dissolving in methylene chloride $(10 \mathrm{ml})$ by continuous stirring. The viscous solution was casted on a petridish to obtain a thin polymeric film and the solvent was allowed 
to dry at room temperature. The solid polymeric matrix was stored at room temperature and observed under light microscopy for drug crystallization for one month.

\section{Preparation of polymeric nanospheres}

PLGA nanospheres incorporated with CC was formulated by a modified emulsion-solvent evaporation method similar to that of Kocbek et al. ${ }^{22}$ The required amount of PLGA (200 mg) and CC (30-50 mg) were weighed, dissolved in methylene chloride $(10 \mathrm{ml})$ and thoroughly mixed to get a clear solution. Primary emulsion was prepared by adding sufficient amount of water $(5 \mathrm{ml})$ to the drug solution and stirring at a high speed $(419 \mathrm{~g})$ followed by sonication for short period (20 min). Emulsioncontaining nano-droplets were then added to PVA solution $(5 \% \mathrm{w} / \mathrm{v}, 20 \mathrm{ml})$ and homogenized for $2 \mathrm{~min}$ at $9660 \mathrm{~g}$. The emulsion was further stirred overnight $(12 \mathrm{~h})$ under atmospheric conditions to remove the organic solvent. The obtained dispersion was centrifuged (26832 g, $20 \mathrm{~min}$ ) and the supernatant was decanted. Drug particles on the surface were removed by washing the polymeric particles (twice) with water and freeze dried for $24 \mathrm{~h}$. five formulations were prepared by varying the amount of CC $(30-50 \mathrm{mg})$. Yield was determined by standard protocol.

\section{Entrapment efficiency and drug loading}

Entrapment efficiency and drug loading in PLGA nanospheres were measured by total CC analysis. Briefly, nanospheres were dissolved in $10 \mathrm{ml}$ of methylene chloride, diluted with mobile phase $(50 \mathrm{ml}$ methanol and $20 \mathrm{mM}$ potassium dihydrogen phosphate, 70:30). Methylene chloride was removed from the solution by purging the nitrogen gas at room temperature. The resultant solution was centrifuged, the top layer was separated, and filtered using $0.2 \mu \mathrm{m}$ filter. The concentration of CC was measured by HPLC as described before. The percentage of entrapment efficiency $(\% \mathrm{EE})$ was calculated as \% $\mathrm{EE}=$ (amount of drug entrapped/ amount of drug incorporated) $\times 100$. Similarly, the percentage drug loading ( $\%$ DL) was determined as $\% \mathrm{DL}=$ (amount of drug in nanospheres/ amount of polymer incorporated + amount of drug incorporated) $\times 100 .^{23}$

\section{Determination of drug content}

Accurately weighed amount of nanospheres $(5 \mathrm{mg}$ ) was dissolved in methylene chloride $(2 \mathrm{ml})$, diluted with mobile phase $(20 \mathrm{ml})$ and the methylene chloride was evaporated by removing nitrogen. Furthermore, mobile phase containing CC was centrifuged and the upper layer was filtered using $0.2 \mu \mathrm{m}$ filter. Adequate amount of mobile phase was added to the filtrate to dilute the drug and the concentration of CC was quantified by HPLC. The drug concentration was calculated based on the $\%$ drug load.

\section{Particle size characterization and zeta potential}

Particle size, size distribution, polydispersity index and zeta potential of nanospheres were determined using dynamic light scattering technique with a Zetasizer (Nano-ZS, Malvern, Westborough, MA). Polymeric nanoparticles were dispersed in deionized water at room temperature by sonication (1 $\mathrm{min}$ ) before analysis to reduce aggregation between nanospheres. Particle sizes (volume weighted mean diameter) were measured.

\section{Scanning electron microscope (SEM)}

The external morphology of nanospheres was carried out using SEM. Samples were diluted, mounted on a metal stubs and gold-coated in a neutral environment of argon maintained under pressure. ${ }^{24}$ Pictures were acquired under different magnification using SEM (Jeol 457V, Tokyo, Japan).

\section{Transmission electron microscopy (TEM)}

The size, shape and dispersion (morphological features) of nanospheres was characterized by TEM using JEOL JEM-1230 TEM (JEOL, Tokyo, Japan). Samples were suspended in water $(1 \mathrm{mg} / \mathrm{ml})$, added on copper grid and stained with uranyl acetate $(1 \% \mathrm{w} / \mathrm{v})$. Extra liquid was cleaned, air dried and analyzed using TEM at $80 \mathrm{kV}$.

\section{In vitro release and kinetics}

The release of CC from drug-loaded nanospheres was assessed by dialysis bag method. The release media used were $0.1 \mathrm{~N} \mathrm{HCl}$ (for $2 \mathrm{~h}$ ) and phosphate buffer ( $\mathrm{pH} 6.8$ for $12 \mathrm{~h}$ ) with $0.7 \%$ of Tween 20 as surfactant to establish sink condition at a concentration of $10 \mu \mathrm{g} / \mathrm{ml} .{ }^{10}$ Twenty five milligrams of nanospheres was dispersed in water (1 $\mathrm{ml}$ ) containing $\mathrm{CC}$ and inserted in dialysis tube (molecular weight cut off 12,000 to 14,000 ). The dialysis tube was placed in a receiving compartment containing 250 $\mathrm{ml}$ of media, which was continuously stirred with magnetic stirrer at $37 \pm 0.5^{\circ} \mathrm{C}$. Samples were withdrawn at regular time intervals $(1,2,3,4,6$ and $8 \mathrm{~h})$ to determine the concentration of the drug. All the samples were filtered using $0.2 \mu \mathrm{m}$ filter and the concentrations of CC release was measured by the HPLC. CC released from nanoparticles was assessed kinetically by means of various mathematical models. ${ }^{25}$

\section{Bioavailability studies}

The oral bioavailability of CC in optimized drug-loaded nanospheres was determined on Sprague-Dawley rats (225-275 g) with a single dose. Animals, under fasting 
condition for $12 \mathrm{~h}$ with free access to water, were divided into two groups (six animals in each group) (IAEC/ SSP/16/PR-005). Nanospheres (1 $\mathrm{mg}$ of CC) were administered to group 1 animals by oral route using gavage. Similarly, the aqueous suspension of CC $(1 \mathrm{ml}$ dose of $1 \mathrm{mg}$ ) was administered to group 2 (control) animals. The dose of CC (1 mg) was determined with its human dose $(32 \mathrm{mg} / \mathrm{kg})$ used for congestive heart failure, using an equation described by Nair and Jacob. ${ }^{26}$ The oral bioavailability of CC nanospheres was estimated from plasma drug level at specific time intervals. Blood sampling $(\sim 200 \mu \mathrm{L})$ from rats was done from lateral tail vein at 1, 2, 4, 6, 8, 12, 18 and $24 \mathrm{~h}$. The samples were treated with the equivalent amount of acetonitrile and 2-propanol, centrifuged (10 $\mathrm{min})$ and the upper layer was filtered using $0.2 \mu \mathrm{m}$ filter. The concentration of CC release was measured by HPLC. An additional calibration curve was developed in the rat plasma by injecting 20-800 ng of the drug. The pharmacokinetic parameters were estimated by no compartmental pharmacokinetic model. ${ }^{23}$

\section{Data analysis}

Data observed were analyzed for statistical significance by one-way analysis of variance (ANOVA) and unpaired t-test (GraphPad Prism, California, USA). In all cases, post-hoc comparisons of the means of individual groups were performed using Dunn's test. ${ }^{27}$ All the measurements were mean of six experiments and data were considered significant when $\mathrm{P}$ value was less or equal to 0.05 .

\section{RESULTS AND DISCUSSION}

The low oral bioavailability of CC could be linked to its unfavorable physicochemical properties such as high MW $(610 \mathrm{~g} / \mathrm{mol})$, low aqueous solubility $(\sim 0.05 \mu \mathrm{g} / \mathrm{ml})$, high lipophilicity ( $\log \mathrm{P}=6.1)$, low $\mathrm{pKa}$ (2.97), low permeability ( $\mathrm{P}_{\text {app }}$ in Caco-2 cells; $2.11 \times 10^{-6} \mathrm{~cm} / \mathrm{sec}$ ) etc. $^{28}$ In addition, the 'rule of five' was broken thrice by this negative physicochemical properties $(\log \mathrm{P}, \mathrm{MW}$ and hydrogen bond acceptors) in case of this drug. Therefore, the conventional method for effective oral delivery of $\mathrm{CC}$ is difficult and requires an alternative approach to overcome all the major challenges to achieve adequate drug delivery. Hence, the encapsulation of drugs into polymeric carrier systems of nano size is a viable pharmaceutical formulation alternative. It is well established that nanospheres formulated with suitable polymers are better at attaining controlled drug release and greater bioavailability. Given these background, biodegradable polymer such as PLGA has been studied extensively and is often used as a drug delivery carrier. ${ }^{29}$ This is majorly due to its distinct properties such as biocompatibility, biodegradability, potential to provide controlled release as well its effectiveness in improving the oral bioavailability. ${ }^{30}$ Considering the significant contribution of PLGA in drug delivery development, this study assessed its feasibility to develop a nanoparticulate system for effective delivery of CC. Preliminary studies were carried out to assess the solubility of CC in PLGA, and our finding suggests that the highest solubility (absence of crystals during one month) was detected when the concentration of CC was $20 \mathrm{mg} / 100 \mathrm{mg}$ of PLGA. However, the drug concentration of $>25 \mathrm{mg}$ showed existence of crystals in film after a week, when observed under light microscopy. It should be emphasized that solubility of drug molecule in a polymer depends on physicochemical properties (MW, chemical nature) of actives and polymer in addition to their possible interaction. Based on solubility data, five different formulations of nanospheres were developed (C1-C5) with varying concentrations of drug (30-50 mg), while amount of PLGA $(200 \mathrm{mg})$ and concentration of PVA were fixed $(5 \% \mathrm{w} / \mathrm{v})$ (Table 1$)$. CC contain polymeric nano spheres were prepared by emulsion-solvent evaporation method using methylene chloride as solvent. The parameters such as stirring speed and duration of sonication were optimized to obtain polymeric particles of nano range. The ratio of drug: polymer used for the formulation of nanospheres is summarized in Table 1. Our findings from the assessment of physicochemical properties of the prepared nanospheres for CC are summarized in Table 2 . The percentage yield $(\sim 70-80 \%)$ was relatively high, and this appear to substantiate the suitability of this alternative formulation method. ${ }^{31}$ In addition, there was no significant difference in the percentage yield between the five formulations (C1-C5), and this is probably because of the low variation in the ratios of drug to polymer (1:4 to 1:6.6) (Table 1). Drug entrapment is an important parameter in nano drug delivery that optimizes therapeutic efficacy of the encapsulated drug. Encapsulation of CC in PLGA was assessed by determining entrapment efficiency and was summarized in Table 2. Common organic solvents like petroleum ether, methylene chloride, chloroform, ethyl acetate and methanol ${ }^{32}$ with HPLC mobile phase were tried to dissolve the nanospheres and the combination of methylene chloride with greater recovery was adopted. The overall percentage efficiency (55-70\%) obtained (Table 2) was certainly high, and is probably related to the fact that the entrapment potential of a polymer mostly depends on the partition coefficient of the pharmaceutical active, affinity of the hydrophobic actives with the PLGA, as well as its solubility in specific polymer. ${ }^{33}$ This observation 


\begin{tabular}{|c|c|c|c|c|}
\hline \multicolumn{4}{|c|}{ Table 1: Composition of candesartan cilexetil loaded polymeric nanospheres } \\
\hline Formulation & Drug (mg) & Polymer (mg) & $\begin{array}{c}\text { Drug: polymer } \\
\text { Ratio }\end{array}$ & $\begin{array}{c}\text { Polyvinyl alcohol (\% } \\
\text { w/v) }\end{array}$ \\
\hline C1 & 30 & 200 & $1: 6.6$ & 5 \\
\hline C2 & 35 & 200 & $1: 5.7$ & 5 \\
\hline C3 & 40 & 200 & $1: 5$ & 5 \\
\hline C4 & 45 & 200 & $1: 4.4$ & 5 \\
\hline C5 & 50 & 200 & $1: 4$ & 5 \\
\hline
\end{tabular}

Table 2: Physicochemical characteristics of candesartan cilexetil loaded polymeric nanospheres*

\begin{tabular}{|c|c|c|c|c|c|c|c|}
\hline Formulations & $\%$ yield & $\%$ EE & $\begin{array}{l}\% \text { Drug } \\
\text { loading }\end{array}$ & $\begin{array}{l}\% \text { Drug } \\
\text { content }\end{array}$ & $\begin{array}{c}\text { Mean } \\
\text { diameter }(\mathrm{nm})\end{array}$ & $\begin{array}{l}\text { Zeta potential } \\
\qquad(\mathrm{mV})\end{array}$ & Polydispersity \\
\hline $\mathrm{C} 1$ & $75.75 \pm 5.18$ & $66.61 \pm 4.62$ & $8.95 \pm 3.61$ & $93.32 \pm 4.18$ & $280 \pm 15$ & $-25.94 \pm 1.65$ & $0.18 \pm 0.07$ \\
\hline $\mathrm{C} 2$ & $76.34 \pm 6.32$ & $68.73 \pm 3.15$ & $9.64 \pm 2.75$ & $95.62 \pm 2.75$ & $310 \pm 20$ & $-26.62 \pm 2.02$ & $0.21 \pm 0.06$ \\
\hline $\mathrm{C} 3$ & $78.43 \pm 5.94$ & $69.44 \pm 4.91$ & $11.57 \pm 3.42$ & $95.60 \pm 2.46$ & $310 \pm 18$ & $-26.41 \pm 1.38$ & $0.18 \pm 0.05$ \\
\hline $\mathrm{C} 4$ & $75.10 \pm 6.12$ & $62.06 \pm 4.28$ & $11.40 \pm 3.17$ & $88.06 \pm 4.67$ & $325 \pm 22$ & $-27.23 \pm 2.16$ & $0.17 \pm 0.04$ \\
\hline C5 & $73.82 \pm 5.36$ & $55.97 \pm 2.65$ & $11.19 \pm 2.90$ & $90.05 \pm 5.11$ & $330 \pm 27$ & $-26.55 \pm 2.38$ & $0.17 \pm 0.06$ \\
\hline
\end{tabular}

*Mean \pm S.D, \% yield: Percentage yield, \%EE: Encapsulation efficiency

is in agreement with earlier reports wherein emulsionevaporation method generally exhibited higher entrapment efficiency. ${ }^{31}$ The high partition coefficient and polymer solubility of $\mathrm{CC}$ also might have favored its entrapment. However, the greater entrapment efficiency $(65-70 \%)$ was observed when the amount of drug was low (C1-C3), compared to the higher drug concentrations ( $\sim 62 \%$ and $\sim 56 \%$ with $\mathrm{C} 4$ and $\mathrm{C} 5$ respectively). Thus, it seems that the drug entrapment has reached saturation (in C3 formulation), and further attempt to increase drug concentration could reduce the entrapment efficiency. A similar trend (higher drug loading with C3 formulation and decreased with C4 and C5 formulations) was noticed with percentage drug loading as well (Table 2).

Drug concentration is an important parameter that symbolizes the content uniformity and efficiency of formulations, and official compendiums endorsed the test of content uniformity in finished drug products to ensure that the drug concentration was with in limit. ${ }^{34}$ Formulations $\mathrm{C} 1-\mathrm{C} 3$, showed $>90 \%$ drug concentration, while a lesser drug concentration was obtained in $\mathrm{C} 4$ and C5 (Table 2). The low standard deviations obtained with the formulations (C1-C5) suggest that the drug concentration is comparable among different batches.

Particle size and size range of the polymeric nanoparticles (C1-C5), determined by dynamic light scattering method, showed the particles in nano size (190-500 nm) with a mean diameter ranged from 280 to $330 \mathrm{~nm}$ (Table 2). Our findings suggest a minor increase in the particle size when drug concentration was high. Figure 1 represents size range of polymeric nanospheres of formulation
C3. Zeta potential measurement is an important property of polymeric particles, as it indicates the surface charge which is directly related to the particle stability in dispersion. Similarly, polydispersity index (value between 0 and 1) is generally determined to assess the width of size distribution. In the current study, measured mean zeta potential $(\sim-25$ to $-27 \mathrm{mV})$ and polydispersity index ( 0.17 to 0.21 ) values for the different formulations were comparable (Table 2). The negative zeta potential values that were observed indicate the presence of free carboxylic end groups of polymer on the surface of the nanospheres. On the other hand, the low polydispersity index values (0.17-0.21) suggest that the particles would have narrow distribution and no agglomeration, as shown in Figure 1 and 2.

The morphological features of the prepared nanospheres (C1-C5) assessed by SEM as well as TEM revealed that the nanospheres possess regular spherical shape with no aggregation. Furthermore, the average particle sizes measured with TEM images were also consistent with the values measured by the particle size analyzer. In addition, no difference was observed in the morphology among the prepared nanoparticles (Data not shown). A representative SEM and TEM images of C3 formulation with average particle size of $\sim 300 \mathrm{~nm}$ is shown in Figure 2. The formulation C3 which showed a higher yield, entrapment efficiency and drug loading, this was used for release and in vivo studies.

The release of a drug from a formulation is a prerequisite for absorption as well as therapeutic activity. The assessment of the release will provide the real time fate 


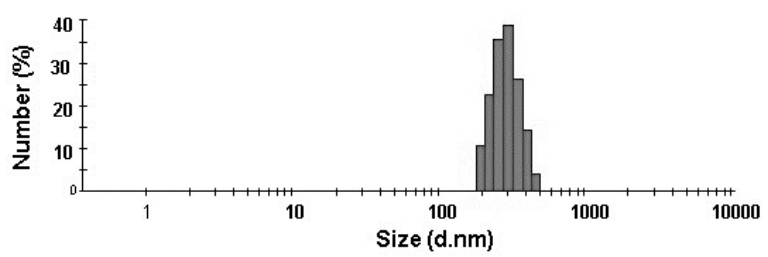

Figure 1: Histogram showing the size distribution of candesartan cilexetil incorporated polymeric nanospheres (formulation C3).
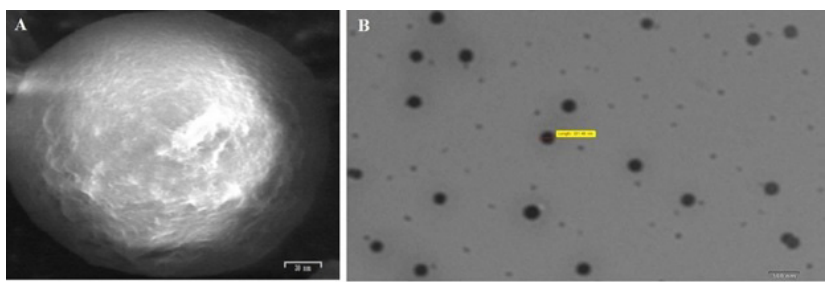

Figure 2: Representative scanning electron microscopy (A) and transmission electron microscopy (B) images of candesartan cilexetil incorporated polymeric nanospheres (formulation C3).

of the encapsulated drug in the nanospheres. However, the drugs incorporated in polymer generally exist as a solid solution, metastable molecular dispersion or amorphous form, and will enhance the solubility and dissolution. On the other hand, PLGA copolymers are degradable by diffusion and erosion or biodegradable through the cleavage of ester linkages to release the actives. In the current study, the drug release from the formulated nanospheres (C3) and pure drug (control) were determined by dialysis method. Figure 3 compares profile of CC release from the selected nanospheres formulation (C3) and the pure drug. It is apparent from Figure 3 that the release profile of nanospheres appeared significantly different $(\mathrm{P}<0.001)$ from the pure drug. The release of CC from nanospheres also showed a biphasic pattern, with an initial burst $(\sim 50 \%$ in $4 \mathrm{~h}$ ) followed by a slower rate and prolonged till $14 \mathrm{~h}$. The rapid release of the drug observed appeared due to the drug molecules embedded close to the surface of polymeric layer of nanospheres. Furthermore, the slow release could be attributed to the affinity of CC for the PLGA, as well as the slow diffusion through the polymeric matrix of lipophilic CC encapsulated in the deeper area of nanospheres. ${ }^{30}$ One possibility for the complete drug release observed in $14 \mathrm{~h}$ is likely due to the moderate hydrophilic nature of PLGA used (50:50). In contrast, the control (pure CC) exhibited slow, low and incomplete release $(\sim 54 \%)$ until end of the study period $(14 \mathrm{~h})$, and this appears due to its low water solubility and high partition coefficient.

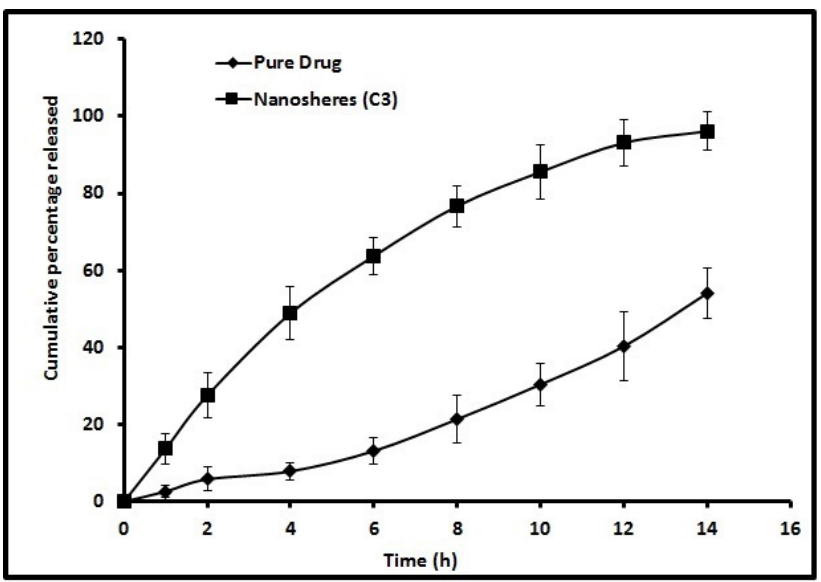

Figure 3: Comparison of cumulative percentage of candesartan cilexetil released from selected nanospheres (C3) and pure drug at various time intervals. Experiments were carried out by dialysis bag method in $0.1 \mathrm{~N} \mathrm{HCl}$ (for $2 \mathrm{~h}$ ) and phosphate buffer ( $\mathrm{pH} 6.8$ for $12 \mathrm{~h}$ ). The value represents average of six trials \pm SD.

The in vitro efficacy of the prepared nanospheres (C3) which was evaluated kinetically using the percentage drug released with different mathematical models (zero-order, first-order, Hixson-Crowell, Higuchi, and KorsmeyerPeppas) showed that the Korsmeyer-Peppas model with the higher regression coefficient $\left(r^{2}\right)$ values $(0.981)$ was considered as the best fit model. Therefore, it can be said that the most suitable model to describe the release of CC from nanospheres (C3) is Korsmeyer-Peppas model. Furthermore, the observed release exponent value ( $\mathrm{n}=0.74$, which is $0.43<\mathrm{n}<0.85$ for spheres) indicate that the diffusion mechanism from nanospheres is anomalous transport.

The final phase of study investigated the bioavailability of selected nanospheres (formulation C3) in comparison to the oral suspension of $\mathrm{CC}$ in rats. Pharmacokinetic parameters such as area under plasma - drug concentration time profile (AUC), maximum concentration of $\operatorname{drug}\left(\mathrm{C}_{\max }\right)$, time to reach maximum concentration $\left(\mathrm{T}_{\max }\right)$, elimination rate constant $\left(\mathrm{K}_{\mathrm{e}}\right)$ and elimination half-life $\left(\mathrm{t}_{1 / 2}\right)$ were analyzed by using a non-compartmental method. Figure 4 compares the mean plasma concentration versus time profiles of CC encapsulated Nano spheres as well as their control. The estimated pharmacokinetic parameters are summarized in Table 3. It is evident from Figure 4 that the kinetic profile of the nanospheres is clearly different from that of the control. The plasma drug concentration was also significantly higher $(\mathrm{P}<0.001)$ for nanospheres at all-time points assessed. Indeed, the nanospheres showed greater absorption from the first hour $(102.58 \pm 33.57 \mathrm{ng} / \mathrm{ml})$ and reached peak at $4 \mathrm{~h}$ (Table 3 ), showing greater effectiveness and 
Table 3: Comparison of mean pharmacokinetic parameters for candesartan

cilexetil in plasma following oral administration of drug loaded nanospheres (C3)

and control ( 1 $1 \mathrm{ml}$, dose of $32 \mathrm{mg} / \mathrm{kg})$ in rats $(\mathrm{n}=6)$.

\begin{tabular}{|c|c|c|}
\hline Parameter & Nanospheres (C3) & Suspension \\
\hline $\mathrm{T}_{\max }(\mathrm{h})$ & 4.0 & 6.0 \\
\hline $\mathrm{C}_{\max }(\mathrm{ng} / \mathrm{ml})$ & $599.92 \pm 139.36^{*}$ & $261.39 \pm 52.06$ \\
\hline $\mathrm{AUC}_{0-\mathrm{t}}(\mathrm{ng} \cdot \mathrm{h} / \mathrm{ml})$ & $6392.10 \pm 1082.24^{\star *}$ & $2165.72 \pm 367.15$ \\
\hline $\mathrm{AUC}_{0-\mathrm{a}}(\mathrm{ng} \cdot \mathrm{h} / \mathrm{ml})$ & $6752.30 \pm 1236.47^{* *}$ & $2256.83 \pm 421.24$ \\
\hline $\mathrm{t}_{1 / 2}(\mathrm{~h})$ & $8.07 \pm 0.28$ & $8.09 \pm 0.16$ \\
\hline $\mathrm{K}_{\mathrm{el}}$ & $0.09 \pm 0.78$ & 0.52 \\
\hline
\end{tabular}

$* \mathrm{P}<0.0005 ; * * \mathrm{P}<0.0001$

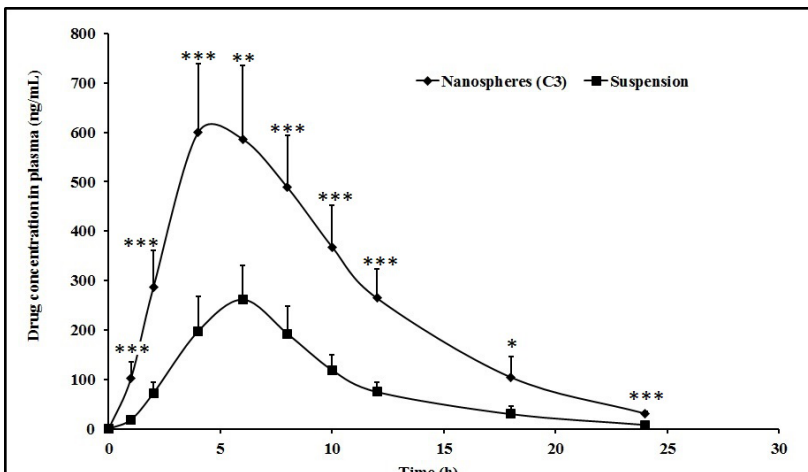

Figure 4: Comparison of mean plasma profiles of candesartan cilexetil following oral delivery of nanospheres (C3) and control (suspension) in rats. The value represents average of six trials $\pm \mathrm{SD}$. ${ }^{*} \mathrm{P}<0.005$; ${ }^{* *} \mathrm{P}<0.001$; ${ }^{* *} \mathrm{P}<0.0001$

efficiency of nanospheres-loaded CC. In contrast, the control (oral suspension) showed low concentration in the initial hour $(18.66 \pm 7.22 \mathrm{ng} / \mathrm{ml})$, slow and low absorption which extended till $6 \mathrm{~h}\left(\mathrm{~T}_{\max }\right)$. The mean $\mathrm{C}_{\max }$ values of the nanospheres treated rats was $599.92 \pm$ $139.36 \mathrm{ng} / \mathrm{ml}$, and this is $\sim 2.3$ folds higher than that of the control $(\mathrm{P}<0.0005)$. Greater and rapid absorption of the CC observed could be probably due to the higher dissolution of drug obtained with the nanospheres. This observation also suggests that the bioavailability of CC is primarily due to solubility and adequate permeability. The drug plasma concentration appeared to decrease in both groups in a similar fashion following the absorption (Figure 4). The elimination rate constant $\left(\mathrm{K}_{\mathrm{e}}\right)$ and elimination half-life $\left(\mathrm{t}_{1 / 2}\right)$ were comparable (Table 3). However, the mean $\mathrm{AUC}_{0-\infty}$ values in the nanospheres treated rats were $\sim 3$ folds $(\mathrm{P}<0.0001)$ higher than CC in oral suspension, suggesting 300\% increase in bioavailability (Table 3 ). These results suggest that the CC loaded nanospheres are clearly better than the conventional formulation. Our findings appear generally consistent with the established fact in the literature that PLGA particles provides mucoadhesion by different mechanisms and these are linked better to better absorption..$^{20}$ Furthermore, several studies have demonstrated that PLGA nanoparticles are taken up by membranous epithelial cells (M-cells) of the Peyer's patches in the gut-associated lymphoid tissue as well as by gut enterocytes. ${ }^{35}$ Thus, the possible reasons for the observed increase in the bioavailability by $\mathrm{CC}$ nanospheres could be due to the higher dissolution, mucoadhesion and/or uptake by Peyer's patches. However, these need to be clearly established in future studies.

\section{CONCLUSION}

PLGA-based nanoparticles appear to be an important and promising formulation approach to improve the oral bioavailability of therapeutic actives which are otherwise less absorbed. The physicochemical properties of the CC loaded polymeric nanospheres were significantly improved and these resulted in rapid and higher dissolution. The rate and extent of drug transport to the systemic circulation from nanospheres was significantly higher, although the exact mechanism needs to be further investigated. Future studies are required to verify the actual improvement in therapeutic outcome of CC loaded biodegradable nanospheres during clinical application.

\section{ACKNOWLEDGEMENT}

The authors acknowledge the Deanship of Scientific Research, King Faisal University (project No. 160007) for the financial support.

\section{CONFLICTS OF INTEREST}

The authors report no conflicts of interest.

\section{ABBREVIATION USED}

AUC: Area under plasma-drug concentration time profile; CC: Candesartan cilexetil; $\mathbf{C}_{\max }$ : Maximum concen- 
tration of drug; DL: Drug loading; EE: Entrapment efficiency; HPLC: High performance liquid chromatography; Kel: Elimination rate constant; MW: Molecular weight; PLGA: poly(lactic acid-co-glycolic acid); SEM: Scanning electron microscope; $\mathbf{t}_{1 / 2}$ : Elimination half-life; TEM: Transmission electron microscopy; $\mathbf{T}_{\text {max }}$ : time to reach maximum concentration.

\section{REFERENCES}

1. Laslett LJ, Alagona P, Clark BA, Drozda JP, Saldivar F, Wilson SR, Poe C, Hart M. The worldwide environment of cardiovascular disease: prevalence, diagnosis, therapy, and policy issues: a report from the American College of Cardiology. Journal of the American College of Cardiology. 2012;60(25):S1-49. https://doi.org/10.1016/j.jacc.2012.11.002; PMid:23257320.

2. Takır S, Altun IH, Sezgi B, Süzgeç-Selçuk $S$, Mat $A$, Uydeş-Do-an BS. Vasorelaxant and blood pressure lowering effects of alchemilla vulgaris: A comparative study of methanol and aqueous extracts. Pharmacognosy magazine. 2015;11(41):163. https://doi.org/10.4103/0973-1296.149733. PMid:25709228 PMCid:PMC4329619.

3. Gundamaraju R, Vemuri RC, Singla RK, Manikam R, Rao AR, Sekaran $\mathrm{SD}$. Strophanthus hispidus attenuates the Ischemia-Reperfusion induced myocardial Infarction and reduces mean arterial pressure in renal artery occlusion. Pharmacognosy magazine. 2014;10(Suppl 3):S557.https://doi. org/10.4103/0973-1296.139782; PMid:25298674 PMCid:PMC4189272

4. Siddam H, Kotla NG, Maddiboyina B, Singh S, Sunnapu O, Kumar A, Sharma D. Formulation and evaluation of atenolol floating bioadhesive system using optimized polymer blends. Int J Pharm Investig. 2016; 6(2):116-22. https:// doi.org/10.4103/2230-973X.177832; PMid:27051631 PMCid:PMC4797488.

5. Ruilope LM, Rosei EA, Bakris GL, Mancia G, Poulter NR, Taddei S, Unger T, Volpe M, Waeber B, Zannad F. Angiotensin receptor blockers: therapeutic targets and cardiovascular protection. Blood pressure. 2005;14(4):196-209. https://doi.org/10.1080/08037050500230227.; PMid:16126553.

6. Muhammad SA, Fatima N. In silico analysis and molecular docking studies of potential angiotensin-converting enzyme inhibitor using quercetin glycosides. Pharmacognosy magazine. 2015;11(Suppl 1):S123. https://doi. org/10.4103/0973-1296.157712.; PMid:26109757 PMCid:PMC4461951.

7. Husain A, Azim Md Sabir, Mitra M, Bhasin PS. A review on Candesartan: Pharmacological and pharmaceutical profile. J Appl Pharm Sci 2011;1(10):1217.

8. Easthope SE, Jarvis B. Candesartan cilexetil: An update of its use in essential hypertension. Drugs 2002;62(8):1253-87. https://doi.org/10.2165/00003495200262080-00016.

9. Deepthi Y, Murthy TG. Design and development and evaluation of candesartan cilexetil liquid filling formulations. International journal of pharmaceutical investigation. 2015;5(2):81. https://doi.org/10.4103/2230973X.153382; PMid:25838992 PMCid:PMC4381390.

10. Hoppe K, Sznitowska M. The effect of polysorbate 20 on solubility and stability of candesartan cilexetil in dissolution media. AAPS PharmSciTech. 2014; 15(5):1116-25. https://doi.org/10.1208/s12249-014-0109-8I; PMid:24871550 PMCid:PMC4179655.

11. Gleiter $\mathrm{CH}$, Mörike KE. Clinical pharmacokinetics of candesartan. Clinical pharmacokinetics. 2002;41(1):7-17. https://doi.org/10.2165/00003088200241010-00002; PMid:11825094.

12. Gao F, Zhang Z, Bu H, Huang Y, Gao Z, Shen J, et al. Nano emulsion improves the oral absorption of candesartan cilexetil in rats: Performance and mechanism. J Control Release. 2011;149(2):168-74. https://doi. org/10.1016/j.jconrel.2010.10.013; PMid:20951749.

13. Zhang Z, Gao F, Bu H, Xiao J, Li Y. Solid lipid nanoparticles loading candesartan cilexetil enhance oral bioavailability: in vitro characteristics and absorption mechanism in rats. Nanomedicine: Nanotechnology, Biology and Medicine. 2012;8(5):740-7. https://doi.org/10.1016/j.nano.2011.08.016; PMid:21930110.
14. Nair AB, Gupta R, Kumria R, Jacob S, Attimarad M. Formulation and evaluation of enteric coated tablets of proton pump inhibitor. Journal of basic and clinical pharmacy. 2010;1(4):215. PMid:24825991 PMCid:PMC3979213.

15. Nair AB, Attimarad M, Al-Dhubiab BE, Wadhwa J, Harsha S, Ahmed M. Enhanced oral bioavailability of acyclovir by inclusion complex using hydroxypropyl-ß-cyclodextrin. Drug delivery. 2014;21(7):540-7. https://doi.or g/10.3109/10717544.2013.853213; PMid:24215288.

16. Kamboj S, Bala S, Nair AB. Solid lipid nanoparticles: An effective lipid based technology for poorly water soluble drugs. Intl J Pharm Sci Rev Res 2010;5(2):78-90.

17. Wadhwa J, Nair A, Kumria R. Emulsion forming drug delivery system for lipophilic drugs. Acta Pol Pharm. 2012;69(2):179-91. PMid:22568032

18. Gharib A, Faezizadeh Z. In vitro anti-telomerase activity of novel lycopeneloaded Nanospheres in the human leukemia cell line K562. Pharmacognosy magazine. 2014;10(37):157. https://doi.org/10.4103/0973-1296.127368; PMid:24914298 PMCid:PMC4047593.

19. Jin X, Zhang SB, Li SM, Liang K, Jia ZY. Influence of chitosan nanoparticles as the absorption enhancers on salvianolic acid $\mathrm{B}$ In vitro and In vivo evaluation. Pharmacognosy Magazine. 2016;12(45):57. https://doi.org/10.4103/09731296.176047; PMid:27019562 PMCid:PMC4787338.

20. Ensign LM, Cone R, Hanes J. Oral drug delivery with polymeric nanoparticles: the gastrointestinal mucus barriers. Advanced Drug Delivery Reviews. 2012;64(6):557-70. https://doi.org/10.1016/j.addr.2011.12.009; PMid:22212900 PMCid:PMC3322271.

21. Peepliwal AK, Bonde CG, Mohanraj K. Bioanalytical method development and its validation for determination of candesartan cilexetil by high performance liquid chromatography with UV detection. Acta Pharm Sci 2010;52(3):247-253.

22. Kocbek P, Obermajer N, Cegnar M, Kos J, Kristl J. Targeting cancer cells using PLGA nanoparticles surface modified with monoclonal antibody. Journal of Controlled Release. 2007;120(1):18-26. https://doi.org/10.1016/j. jconrel.2007.03.012; PMid:17509712.

23. Nair AB, Kaushik A, Attimarad M, Al-Dhubiab BE. Enhanced oral bioavailability of calcium using bovine serum albumin microspheres. Drug delivery. 2012;19(6):277-85. https://doi.org/10.3109/10717544.2012.704094 ; PMid:22928732.

24. Kumria R, Nair AB, Al-Dhubiab BE. Loratidine buccal films for allergic rhinitis: development and evaluation. Drug development and industrial pharmacy. 2014; 40(5):625-31. https://doi.org/10.3109/03639045.2014.884125 PMid:24506459.

25. Nair A, Gupta R, Vasanti S. In vitro controlled release of alfuzosin hydrochloride using HPMC-based matrix tablets and its comparison with marketed product. Pharmaceutical development and technology. 2007;12(6):621-5. https://doi. org/10.1080/10837450701563277; PMid:18161635.

26. Nair AB, Jacob S. A simple practice guide for dose conversion between animals and human. Journal of basic and clinical pharmacy. 2016;7(2):27. https://doi. org/10.4103/0976-0105.177703; PMid:27057123 PMCid:PMC4804402.

27. Nair AB, Sammeta SM, Vaka SRK, Murthy SN. A study on the effect of inorganic salts in transungual drug delivery of terbinafine. J Pharm Pharmacol 2009;61(4):431-437. https://doi.org/10.1211/jpp.61.04.0003; PMid:19298688.

28. Zhou L, Chen X, Gu Y, Liang J. Transport characteristics of candesartan in human intestinal Caco-2 cell line. Biopharmaceutics \& drug disposition. 2009;30(5):259-64. https://doi.org/10.1002/bdd.664; PMid:19562680.

29. Danhier F, Ansorena E, Silva JM, Coco R, Le Breton A, Préat V. PLGA-based nanoparticles: an overview of biomedical applications. Journal of controlled release. 2012;161(2):505-22. https://doi.org/10.1016/j.jconrel.2012.01.043; PMid:22353619.

30. Makadia HK, Siegel SJ. Poly lactic-co-glycolic acid (PLGA) as biodegradable controlled drug delivery carrier. Polymers. 2011;3(3):1377-97. https://doi. org/10.3390/polym3031377; PMid:22577513 PMCid:PMC3347861.

31. Wischke C, Schwendeman SP. Principles of encapsulating hydrophobic drugs in PLA/PLGA microparticles. International Journal of pharmaceutics. 2008 Dec 8;364(2):298-327. https://doi.org/10.1016/j.ijpharm.2008.04.042; PMid:18621492.

32. Versha P, Ghosh B, Anroop B, Ramanjit M. Antimicrobial activity of Alstonia scholaris leaf extracts. Indian drugs. 2003;40(7):412-3.

33. Al-Dhubiab BE, Nair AB, Kumria R, Attimarad M, Harsha S. Formulation and evaluation of nano based drug delivery system for the buccal delivery of 
acyclovir. Colloids and Surfaces B: Biointerfaces. 2015;136:878-84. https:// doi.org/10.1016/j.colsurfb.2015.10.045; PMid:26547315.

34. Kumria R, Nair AB, Goomber G, Gupta S. Buccal films of prednisolone with enhanced bioavailability. Drug delivery. 2016;23(2):471-8. https://doi.org/10. 3109/10717544.2014.920058; PMid:24892626.
35.

Joshi G, Kumar A, Sawant K. Enhanced bioavailability and intestinal uptake of Gemcitabine $\mathrm{HCl}$ loaded PLGA nanoparticles after oral delivery. European Journal of Pharmaceutical Sciences. 2014;60:80-9. https://doi.org/10.1016/j. ejps.2014.04.014; PMid:24810394.

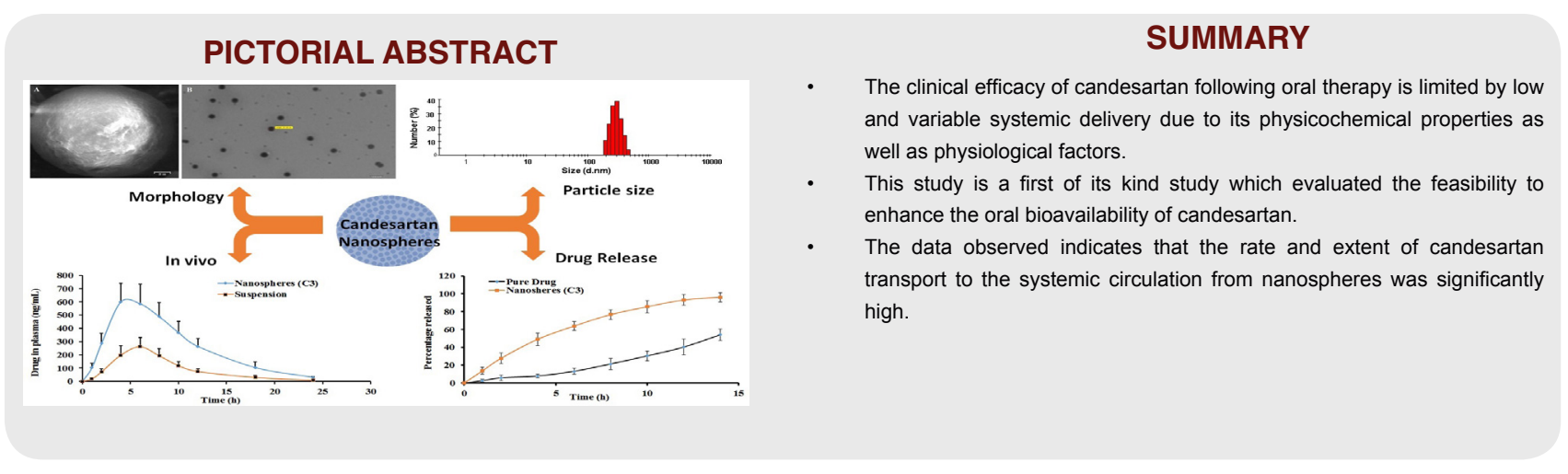

Cite this article: Nair AB, Al-Dhubiab BE, Shah J, Attimarad M, Harsha S. Poly(lactic acid-co-glycolic acid) Nanospheres Improved the Oral Delivery of Candesartan Cilexetil. Indian J of Pharmaceutical Education and Research. 2017;51(4):571-9. 